\title{
Assessment of drug-drug interactions among patients with psychiatric disorders: A clinical pharmacist-led study
}

\author{
Selas Sunny ${ }^{\mathrm{a}}$, Santosh Prabhu ${ }^{\mathrm{b}}$, Sharad Chand ${ }^{\mathrm{a}}$, Nandakumar UP ${ }^{\mathrm{a}}$, Chinju Susan Chacko $^{\mathrm{c}}$, \\ Juno J. Joel ${ }^{\text {a, }}$ \\ a Department of Pharmacy Practice, NGSM Institute of Pharmaceutical Sciences, Nitte (Deemed to be University), Deralakatte, Mangaluru, Karnataka, 575018, India \\ ${ }^{\mathrm{b}}$ Department of Psychiatry, Justice K. S. Hegde Charitable Hospital, Deralakatte, Mangaluru, Karnataka, 575018, India \\ ${ }^{c}$ Department of Pharmacy Practice, College of Pharmaceutical Sciences, Dayananda Sagar University, Bangalore, Karnataka, India
}

\section{A R T I C L E I N F O}

\section{Keywords:}

Drug-drug interactions

Olanzapine

Severity

Polypharmacy

Psychiatric disorders

\begin{abstract}
A B S T R A C T
Background: Drug-drug interaction alters the efficacy of the drugs. Early identification can reduce unintended therapeutic outcomes.

Objective: The main objective of the present study was to assess the drug-drug interactions among patients with psychiatric disorders.

Methodology: A prospective observational study was conducted for a period of eight months. A total of 112 psychiatric inpatients were enrolled in the study. The patients were monitored regularly to identify the incidence of potential and actual drug-drug interactions. The identified interactions were analyzed for their severity by using various standard references which included published scientific articles, online databases (e.g., UpToDate) and standard textbooks.

Results and Discussion: The mean age of the study population in years was found to be $37.93 \pm 12.21$ standard deviation. It was observed that the incidence of potential drug-drug interactions was $66.96 \%$. A total of 201 potential drug-drug interactions were identified from 75 patients. Based on the severity assessment of the identified interactions, $52.73 \%$ were major, $37.31 \%$ were moderate, and $19.82 \%$ were minor. About $7.46 \%$ were contraindicated drug combinations. The data on the onset of interaction revealed that $34.82 \%$ were of delayed onset and $14.92 \%$ with rapid onset and $50.24 \%$ were not specified. The drug that was responsible for the majority of the interactions in the study was found to be olanzapine.

Conclusion: The study revealed a high incidence of drug-drug interaction. Drug-drug interactions most frequently encountered among psychiatric patients were found to be major in terms of severity. The study concluded on the higher event of drug-drug interactions among the patients prescribed with olanzapine.
\end{abstract}

\section{Introduction}

In primary care and clinical settings, the majority of the patients seek medical management for psychiatric illnesses like depression and schizophrenia. ${ }^{1}$ Drug-related problems are a common cause of morbidity and may lead to mortality in serious medical issues. ${ }^{2}$ It has been projected that drug-drug interactions contribute $6 \%-10 \%$ of adverse events and most of them can be prevented through proper monitoring. ${ }^{3}$ Ever since typical antipsychotics were introduced during the 1950s, they have been considered as a cornerstone in the management of schizophrenia and related illness. However, the atypical antipsychotics were considered to have lesser side effects and are more effective, especially in the treatment of some negative symptoms like flattened effect and absence of emotion. ${ }^{4}$ Besides adverse effects, antipsychotics with other concomitant drugs can lead to potential drug-drug interactions (pDDIs) as the patients may have several medications due to comorbidities. ${ }^{5}$ These drug-drug interactions (DDIs) can also cause variation in blood pressure, sedation, central nervous system (CNS) toxicity, cardiac arrhythmias, etc. For various reasons including long-term drug therapy and polypharmacy, it is difficult to avert DDIs among these patients and thus create challenge to the treating physicians.

The consequences of drug interactions can have a negative impact on morbidity, mortality, length of hospitalization, health care cost, and

\footnotetext{
* Corresponding author. Department of Pharmacy Practice, NGSMIPS, Nitte (Deemed to be University), Mangaluru, Karnataka, 575018, India.

E-mail address: junojoel@nitte.edu.in (J.J. Joel).
} 
quality of life. ${ }^{7}$ The common risk factor related to DDIs can be the age and gender of the patient, changes in pharmacokinetic parameters, polypharmacy, medication errors and comorbid conditions. ${ }^{8}$ Identification and minimizing the risk factors substantially prevent the incidence of drug-drug interactions. DDIs are one of the most important reasons behind unexpected clinical responses among the patients, especially those who are on polypharmacy. Vigilant investigation with appropriate substitution and dose reduction may be mandated in various instances to prevent adverse incidences, thereby enhancing the patient safety. Hence, the current study was designed to identify the incidence of drug-drug interactions and to assess its severity among patients with psychiatric disorders.

\section{Materials and methods}

A prospective observational study was conducted in the inpatient units of psychiatry department of Justice K.S. Hegde Charitable Hospital (1000 bedded tertiary care hospital), Mangalore, Karnataka, for a period of eight months from September 2017 to April 2018. The institutional ethics committee of NGSM Institute of Pharmaceutical sciences has approved the study (REF: NGSMIPS/IEC/15/2017-18) before its initiation. A minimum required sample size was reached as 100 at $5 \%$ confidence interval, $10 \%$ precision and $53 \%$ population proportion based on the previous studies. ${ }^{9}$ A suitable data collection form was designed to document the patient-related information, including age, gender, diagnosis, comorbidities and drugs prescribed. Written patient consent was obtained from the patient caretakers before enrolling the patient in the study. The study included all the psychiatric inpatients in the age group of 18-60 years. Pregnant and lactating mothers and patients who were having incomplete medical records were excluded from the study. A total of 112 patients were enrolled for this study and their case records were reviewed on a daily basis. These patients were closely monitored for the development of unusual symptoms. The treating physician confirmed the suspected and potential drug-drug interactions. The identified interactions were analyzed for their severity by using the various standard references, which included published scientific articles, online databases (e.g., UpToDate) and standard textbooks.

The severity of drug-drug interactions were classified as "Major possibly life-threatening and requires intervention," "Moderate - may exacerbate the patient condition, requires therapy modification," and "Minor - potential DDI with limited clinical effect." Clinically significant interactions were those DDIs observed in the patients. In contrast, the potential drug-drug interactions (PDDIs) were those not observed in the patients but gives in signal for the detection of interactions. The moderate and major DDI were intervened, and suitable therapy modifications were made. Descriptive statistical analysis was applied by using the Statistical Package for Social Sciences (SPSS). The enrolled patients' demographic characteristics, like age and gender, were summarized using mean and standard deviation. Potential DDIs among patients, length of hospital stay, disease condition, drugs prescribed, and interactions per patient were summarized in frequency and percentage and presented with the aid of tables. Categorization of drug interactions based on severity, onset and documentation was also summarized using frequency and percentage.

\section{Results}

\subsection{Distribution of the subjects according to their gender and age}

During the study period, it was observed that the admission of male patients $(n=73,65.2 \%)$ was higher than the female patients $(n=39$, $34.8 \%$ ). The mean age of the study population was found to be $37.93 \pm$ $12.21 \mathrm{SD}$. It was identified that the majority of the patients were in the age group of $30-39$ years $(n=34,30.4 \%)$ followed by patients in the age group of $18-29$ years $(n=32,28.6 \%)$. Table 1 summarizes the age-wise distribution of study subjects.
Table 1

Age and gender-wise distribution of the study subjects.

\begin{tabular}{llll}
\hline Age & Male $(\mathrm{n}=73)$ & Female $(\mathrm{n}=39)$ & Total Population $(\mathrm{n}=112)$ \\
\hline $18-29$ & 23 & 9 & 32 \\
$30-39$ & 19 & 15 & 34 \\
$40-49$ & 15 & 9 & 24 \\
$50-59$ & 16 & 6 & 22 \\
Mean \pm SD: $37.93 \pm 12.21$ & & \\
\hline
\end{tabular}

\subsection{Distribution of psychiatric drugs prescribed among the study population}

Among the various antipsychotic agents, olanzapine ( $n=45$, $16.66 \%$ ) was found to be the highest prescribed drug and in the drug category of anxiolytics, lorazepam ( $n=24,8.89 \%)$ was the highest prescribed agent. Among various anticonvulsants, sodium valproate (n $=23,8.51 \%$ ) and in the anticholinergic drug category, trihexyphenidyl ( $n=23,8.51 \%$ ) was found to be the commonly prescribed agent. The average number of psychotropic agents per medication order was found to be 2.7. The details of the psychotropic agents prescribed among the study population are summarized in Table 2.

\subsection{Distribution of potential drug-drug interactions ( $p D D I s$ )}

All the possible drug interactions were studied from the medication orderd of the enrolled patients. Two hundred one possible drug-drug interactions were observed from the medication orders of 112 patients. The most common interacting pair was found to be olanzapine and sodium valproate $(n=12,5.97)$, followed by olanzapine and lorazepam $(\mathrm{n}=11,5.47 \%)$, and trihexyphenidyl and sodium valproate ( $\mathrm{n}$ $=10,4.97 \%)$.

\subsection{Distribution of potential drug-drug interactions based on psychiatric disorders}

In this study, most of the patients were diagnosed with paranoid schizophrenia $(n=20,26.67 \%)$. They were treated with various medications and were found to have a higher possibility of occurrence of drug-drug interactions. The second higher chance was observed among patients of bipolar affective disorder with psychotic symptoms $(n=17$, $22.67 \%$ ), which is followed with bipolar affective disorder without psychotic symptoms $(\mathrm{n}=10,27.02 \%)$. The details are summarized in Table 3.

\subsection{Distribution of common consequences of potential drug-drug interactions}

The common outcomes in relation to pDDIs were studied. It was revealed that in the majority of cases, the consequences would be QT interval prolongation $(n=61)$, followed by an increased risk of torsades de point $(n=25)$, poor control of seizure $(n=16)$, increased anticholinergic effects $(n=15)$. The details are explained in Table 4 .

\subsection{Distribution of potential drug-drug interactions based on its severity}

The study categorized drug-drug interactions based on its severity. They were categorized into major, moderate, minor and contraindicated. It was found that $(\mathrm{n}=106,52.73 \%)$ were major, $(\mathrm{n}=75$, $37.31 \%)$ were moderate, and $(\mathrm{n}=5,2.48 \%)$ were minor in severity. Based on the analysis, it was observed that only $(n=15,7.46 \%)$ were considered contraindicated as it may lead to toxic reactions. 
Table 2

Distribution of psychiatric drugs prescribed in the study population.

\begin{tabular}{|c|c|c|c|c|c|}
\hline Sl. No & Class of drugs & & Drugs & Frequency (n) & Percentage (\%) \\
\hline \multirow[t]{11}{*}{1.} & \multirow[t]{11}{*}{ Antipsychotics } & \multirow[t]{5}{*}{ 1st Generation (Typical, Conventional) Antipsychotics } & Chlorpromazine & 11 & 4.07 \\
\hline & & & Haloperidol & 8 & 2.96 \\
\hline & & & Zuclopenthixol & 8 & 2.96 \\
\hline & & & Fluphenazine & 3 & 1.11 \\
\hline & & & Flupenthixol & 1 & 0.37 \\
\hline & & \multirow[t]{6}{*}{ 2nd Generation (Atypical, Novel) Antipsychotics } & Olanzapine & 45 & 16.66 \\
\hline & & & Risperidone & 21 & 7.77 \\
\hline & & & Quetiapine & 16 & 5.92 \\
\hline & & & Amisulpride & 12 & 4.44 \\
\hline & & & Aripiprazole & 7 & 2.59 \\
\hline & & & Clozapine & 2 & 0.74 \\
\hline \multirow[t]{9}{*}{2.} & \multirow[t]{9}{*}{ Antidepressants } & \multirow[t]{4}{*}{ Selective Serotonin Reuptake Inhibitors (SSRI) } & Escitalopram & 8 & 2.96 \\
\hline & & & Fluoxetine & 4 & 1.48 \\
\hline & & & Sertraline & 3 & 1.11 \\
\hline & & & Fluvoxamine & 2 & 0.74 \\
\hline & & \multirow[t]{3}{*}{ Tricyclic Antidepressants } & Amitriptyline & 1 & 0.37 \\
\hline & & & Imipramine & 1 & 0.37 \\
\hline & & & Clomipramine & 1 & 0.37 \\
\hline & & Serotonin Norepinephrine Reuptake Inhibitors & Venlafaxine & 1 & 0.37 \\
\hline & & Specific Serotonergic Antidepressants & mirtazapine & 1 & 0.37 \\
\hline \multirow[t]{3}{*}{3.} & \multirow[t]{3}{*}{ Anxiolytics and Anticonvulsants } & \multirow[t]{7}{*}{ Benzodiazepines } & Lorazepam & 24 & 8.89 \\
\hline & & & Clonazepam & 15 & 5.56 \\
\hline & & & Diazepam & 5 & 1.85 \\
\hline \multirow[t]{4}{*}{4.} & \multirow[t]{4}{*}{ Mood stabilizers } & & Lithium & 12 & 4.44 \\
\hline & & & Lamotrigine & 2 & 0.74 \\
\hline & & & oxcarbazepine & 2 & 0.74 \\
\hline & & & carbamazepine & 1 & 0.37 \\
\hline \multirow[t]{4}{*}{5.} & \multirow[t]{4}{*}{ Anticonvulsant } & & Sodium valproate & 23 & 8.51 \\
\hline & & & Valproic acid & 4 & 1.48 \\
\hline & & & Topiramate & 2 & 0.74 \\
\hline & & & Phenytoin & 1 & 0.37 \\
\hline \multirow[t]{2}{*}{6.} & Anticholinergic/Antiparkinsonian & & Trihexyphenidyl & 23 & 8.51 \\
\hline & Total & & & 270 & 100 \\
\hline
\end{tabular}

\subsection{Distribution of potential drug-drug interactions based on the time required to develop symptoms}

The potential drug-drug interactions were studied to identify the time required to develop symptoms. The majority of the reactions were found as rapid onset $(\mathrm{n}=30,14.92 \%)$, followed by delayed-type $(\mathrm{n}=$ $70,34.82 \%)$ and $(\mathrm{n}=101,50.24 \%)$ were not specified.

\section{Discussion}

The current study gives an outline of pDDIs and their possible outcomes among psychiatric patients. The majority of patients were males and a total of 201 potential drug-drug interactions were observed from the medication orders of 112 patients. This result was found similar to the study conducted by Rafi M S et al., where a total of 181 pDDIs were identified, out of which the majority of the patients were males $(66.9 \%)$ as compared to their female counterparts. ${ }^{10}$ The mean age of patients in the present study was $37.93 \pm 12.21$, with most of the patients belonging to the age group of 30-39 years. Consequently, the potential drug-drug interactions were widely seen in patients of the same age group. A similar study conducted by Mezgebe HB et al., has shown similar results as the mean age of the studied population was $35.94 \pm$ 16.78 out of 205 patients. $^{6}$

In our study, the most common psychiatric disorder was noticed to be paranoid schizophrenia, followed by bipolar affective disorder with psychotic symptoms and bipolar affective disorder without psychotic symptoms. Comparable results were shown in the studies conducted by Mezgebe HB et al., and Jomo SM et al., where they identified a high incidence of bipolar mood disorder and schizophrenia respectively. ${ }^{6,11}$ Most of the present study patients were prescribed with olanzapine, followed by sodium valproate and trihexyphenidyl. These results were found to be similar to the study conducted by Guo JJ et al., where the maximum number of prescriptions had olanzapine. ${ }^{12}$
Two hundred one possible drug-drug interactions were observed from the medication orders of 112 patients. The most interacting pair was found to be olanzapine and sodium valproate, followed by olanzapine and lorazepam, then trihexyphenidyl and sodium valproate. The study report of Ismail et al., showed that the highest interacting combination was olanzapine with divalproex sodium, followed by haloperidol with promethazine. ${ }^{8}$

Among possible drug-drug interactions, the majority were identified as major drug-drug interactions followed by moderate and minor. A similar study carried out by Nieuwstraten C et al., reported that $52 \%$ of the interactions were moderate, $30 \%$ were major and $14 \%$ were minor interactions. ${ }^{13}$ A majority of the drug interactions were found preventable in nature. Continuous monitoring of therapeutic outcomes, introduction of preventive measures like bagging system and timely clinical pharmacist interventions can reduce the incidence of drug-drug interactions, medication errors and other drug-related problems. ${ }^{14,15}$ This study revealed a high incidence of drug-drug interactions. These interactions were potential in nature and could have been prevented. Vigilant planning by the physician and a clinical pharmacist is the need of the hour to prevent and to control the occurrence of unwanted drug-drug interactions. This study was a part of an academic project and was limited by the small sample size considered for the study.

\section{Conclusion}

The present study estimates the higher chances of potential drugdrug interactions in hospitalized patients with psychiatric disorders. The analysis shows antipsychotics as the major class of drugs that can cause major drug-drug interactions. Olanzapine and sodium valproate (5.97\%) were the most common interacting pairs. It was also noted that QT interval prolongation and cardiotoxicity were the common adverse outcomes of these interacting drug pairs. So it is suggested that patients with cardiac disorders be strictly monitored when co-prescribed with 
Table 3

Frequency of drug-drug interactions based on psychiatric conditions.

\begin{tabular}{|c|c|c|c|c|}
\hline \multicolumn{3}{|c|}{ Type of Psychiatric disorders } & \multirow{3}{*}{$\begin{array}{l}\text { Patients } \\
\text { with DDIs } \\
\mathrm{n}=75 \\
(\%) \\
20 \\
(26.67 \%)\end{array}$} & \multirow{3}{*}{$\begin{array}{l}\text { Patients } \\
\text { without } \\
\text { DDIs n = } \\
37(\%) \\
13 \\
(35.13 \%)\end{array}$} \\
\hline Schizophrenia & Schizophrenia & Paranoid & & \\
\hline \& other & & schizophrenia & & \\
\hline \multirow[t]{8}{*}{$\begin{array}{l}\text { psychotic } \\
\text { disorders }\end{array}$} & & $\begin{array}{l}\text { Undifferentiated } \\
\text { schizophrenia }\end{array}$ & $2(2.67 \%)$ & - \\
\hline & & $\begin{array}{l}\text { Residual } \\
\text { schizophrenia }\end{array}$ & $2(2.67 \%)$ & $1(2.70 \%)$ \\
\hline & & $\begin{array}{l}\text { Acute } \\
\text { schizophrenia }\end{array}$ & $2(2.67 \%)$ & - \\
\hline & $\begin{array}{l}\text { Psychotic } \\
\text { disorders }\end{array}$ & $\begin{array}{l}\text { Psychosis not } \\
\text { specified }\end{array}$ & $5(6.67 \%)$ & $\begin{array}{l}4 \\
(10.81 \%\end{array}$ \\
\hline & & $\begin{array}{l}\text { Other acute and } \\
\text { transient } \\
\text { psychotic } \\
\text { disorders }\end{array}$ & $4(5.33 \%)$ & - \\
\hline & & $\begin{array}{l}\text { Acute } \\
\text { polymorphic } \\
\text { psychotic } \\
\text { disorder }\end{array}$ & - & $2(5.40 \%)$ \\
\hline & & Psychosis & $1(1.33 \%)$ & _- \\
\hline & \multicolumn{2}{|c|}{ Schizoaffective disorder } & $4(5.33 \%)$ & - \\
\hline \multirow[t]{8}{*}{ Mood disorder } & \multicolumn{2}{|l|}{ Mood disorder } & $2(2.67 \%)$ & $2(5.40 \%)$ \\
\hline & \multirow[t]{3}{*}{$\begin{array}{l}\text { Depressive } \\
\text { disorders }\end{array}$} & $\begin{array}{l}\text { Moderate } \\
\text { depression }\end{array}$ & $3(4 \%)$ & $1(2.70 \%)$ \\
\hline & & Mild depression & $3(4 \%)$ & - \\
\hline & & Severe depression & $1(1.33 \%)$ & $1(2.70 \%)$ \\
\hline & \multirow[t]{4}{*}{$\begin{array}{l}\text { Bipolar } \\
\text { disorders } \\
\text { (BPAD) }\end{array}$} & $\begin{array}{l}\text { BPAD with } \\
\text { psychotic } \\
\text { symptom's }\end{array}$ & $\begin{array}{l}17 \\
(22.67 \%\end{array}$ & $\begin{array}{l}4 \\
(10.81 \%\end{array}$ \\
\hline & & $\begin{array}{l}\text { BPAD without } \\
\text { psychotic } \\
\text { symptoms }\end{array}$ & $\begin{array}{l}10 \\
(27.02 \%)\end{array}$ & $3(4 \%)$ \\
\hline & & $\begin{array}{l}\text { Mania with } \\
\text { psychotic } \\
\text { symptoms }\end{array}$ & $1(1.33 \%)$ & $2(5.40 \%)$ \\
\hline & & $\begin{array}{l}\text { Mania without } \\
\text { psychotic } \\
\text { symptoms }\end{array}$ & $2(2.67 \%)$ & - \\
\hline \multirow{2}{*}{$\begin{array}{l}\text { Anxiety } \\
\text { disorders }\end{array}$} & \multicolumn{2}{|c|}{ Obsessive compulsive disorder } & $5(6.67 \%)$ & $3(8.10 \%)$ \\
\hline & \multicolumn{2}{|c|}{ Post-traumatic stress disorder } & $1(1.33 \%)$ & - \\
\hline $\begin{array}{l}\text { Somatoform } \\
\text { disorders }\end{array}$ & \multicolumn{2}{|c|}{$\begin{array}{l}\text { Undifferentiated somatoform } \\
\text { disorder }\end{array}$} & - & $1(2.70 \%)$ \\
\hline \multirow[t]{3}{*}{$\begin{array}{r}\text { Personality } \\
\text { disorders }\end{array}$} & $\begin{array}{l}\text { Borderline } \\
\text { personality } \\
\text { disorder }\end{array}$ & $\begin{array}{l}\text { Emotionally } \\
\text { unstable } \\
\text { personality } \\
\text { disorder }\end{array}$ & $3(4 \%)$ & $1(2.70 \%)$ \\
\hline & Dementia & Mixed dementia & $1(1.33 \%)$ & - \\
\hline & \multicolumn{2}{|l|}{ Seizure disorder } & $2(2.67 \%)$ & - \\
\hline
\end{tabular}

Table 4

Distribution of common consequences of potential drug-drug interactions.

\begin{tabular}{ll}
\hline Consequences of drug interactions & Frequency (n) \\
\hline QT interval prolongation & 61 \\
Increased Torsade's de point & 25 \\
Loss of seizure control and change in valproate concentrations & 16 \\
Increased anticholinergic effects & 15 \\
Decreased olanzapine concentration & 14 \\
Decreased effectiveness and serum concentrations of & 7 \\
phenothiazine's & \\
Increased cardiotoxicity & 6 \\
Increased serotonin syndrome & 2 \\
Other outcomes related to drug serum concentrations & 20 \\
\hline
\end{tabular}

selected antipsychotics. Electronic database systems as a decision support tool and vigilance towards drug selection may help to decrease the problems with pDDIs.

\section{Funding}

Nil.

\section{Declaration of competing interest}

Authors declare no conflict of interest.

\section{Acknowledgment}

We Authors are thankful to the department of psychiatry, Justice K. S. Hegde Charitable Hospital, Nitte (Deemed to be University) for guiding us during the entire research work.

\section{References}

1 Barrett JE, Barrett JA, Oxman TE, Gerber PD. The prevalence of psychiatric disorders in primary care practice. Arch Gen Psychiatr. 1988;45:1100-1106.

2 Roy DA, Shanfar I, Shenoy P, et al. Drug-related problems among chronic kidney disease patients: a pharmacist-led study. Int J Pharmaceutic Res. 2020;12(4):79-84.

3 Kelly WN. Potential risks and prevention, part 2: drug-induced permanent disabilities. Am J Health Syst Pharm. 2001;58:1325-1329.

4 Rawal KB, Chand S, Luhar MB, et al. A comparative study on relative safety and efficacy of chlorpromazine and risperidone. Int J Res Pharm Sci. 2020;11(2): 1539-1544.

5 Chwastiak L, Rosenheck R, Leslie D. Impact of medical comorbidity on the quality of schizophrenia pharmacotherapy in a national VA sample. Med Care. 2006;44:55-61.

6 Mezgebe HB, Sied K. Prevalence of potential drud-drug interactions among psychiatric patients in auder referral hospital, mekelle, tigray, Ethiopia. J Scientific Innovat Res. 2015;4(2):71-75.

7 Gutherie B, Makubate B, Hernandez-Santiago V, Creischulte. The rising tide of polypharmacy and drug-drug interactions: population database analysis 1995-2010. BMC Med. 2015;74(13):1-10.

8 Ismail M, Iqbal Z, Khattak MB, Javaid A, Khan MI, et al. Potential drug-drug interactions in psychiatric ward of a tertiary care hospital: prevalence, levels and association with risk factors. Trop J Pharmaceut Res. 2012;11(2):289-296.

9 Aburamadan HAR, Sridhar SB, Tadross TM. Assessment of potential drug interactions among psychiatric inpatients receiving antipsychotic therapy of a secondary care hospital, United Arab Emirates. "J Adv Pharm Technol Research"'" (JAPTR)". 2021;12 (1):45-51.

10 Rafi MS, Naqwi NBS, Khan MU, Fayyaz M, Asharaf N, et al. Evaluation of potential drug-drug interactions with antidepressants in two tertiary care hospitals. $J$ Clin Diagn Res. 2015;9(7):5-8.

11 Jomo SM, Amugune B, Sinei K, Oluka M. Assessing the prevelance and security of potential drug-drug interactions among mentally ill patients. Indian Res J Pharma Sci. 2016;3(1):331-343.

12 Guo JJ, Wu J, Kelton ML, Jing Y, Patel NC, et al. Exposure to potentially dangerous drug-drug interactions involving antipsychotics. Psychiatr Serv. 2012;63(11): 1080-1088.

13 Nieuwstraten C, Labiris NR, Holbrook A. Systematic overview of drug interactions with antidepressant medications. Can J Psychiatr. 2006;51(5):300-316.

14 Chand S, Shastry CS, Vinay BC, et al. Brown, white, and blue bagging in special pharmacy: an emerging trend to minimize medication error. J Global Pharma Technol. 2019;11(8):1-4.

15 Voora L, Sah SK, Bhandari R, et al. Doctor of pharmacy: boon for healthcare system. Drug Invent Today. 2020;14(1):153-158. 